Chien-Ho Ko and Jiun-De Kuo (2018). "Lean formwork." In: Proc. $26^{\text {th }}$ Annual Conference of the International. Group for Lean Construction (IGLC), González, V.A. (ed.), Chennai, India, pp. 1283-1290. DOI: doi.org/10.24928/2018/0211. Available at: www.iglc.net

\title{
LEAN FORMWORK
}

\author{
Chien-Ho Ko ${ }^{1}$ and Jiun-De Kuo ${ }^{2}$
}

\begin{abstract}
Formwork materials and worker payments are one of the main expenditures in reinforced-concrete structures. Formwork engineering is thus one main factor impacting project success. In current practice, formwork construction including non-value-adding activities results rework and inventory waste. The aim of the paper is to adopt the lean manufacturing ideas to reduce unnecessary waste in the formwork engineering. A lean formwork construction model is developed to achieve this goal. In the lean formwork construction model, an on-site quality control culture is established by using Andon. Using the Andon system, form workers could receive support right away when problem occurs. Moreover, using Andon, operations in formwork engineering are pulled using the Kanban system to lower mold inventory level and create a continuous formwork construction flow. To validate the feasibility of the lean formwork model, a real case is tested. Experimental data demonstrate the developed method could banish unnecessary worker-hours in the formwork's operational flow and enhance formwork's value.
\end{abstract}

\section{KEYWORDS}

Formwork, lean manufacturing, kanban, andon.

\section{INTRODUCTION}

Formwork operations depend heavily on teamwork. However, ageing workers may deteriorate productivity. This worker structural problem directly impact project delivery, quality, and cost (Sutherland 2005; Chang 2007). To improve the aforementioned problems, scholars have suggested alternative materials, such as paper, fabric, fiber, Fiber-Reinforced Plastic (FRP), metal, compound, and composite materials to substitute wooden molds (Arslan et al. 2005; Yip and Poon 2008; Veenendaal et al. 2011; Spottiswoode et al. 2012).

Lean manufacturing is a management philosophy adopted by enterprises for improving work flow in recent years. Construction industry introduced the lean production concept named Lean Construction since 90's (Koskela 1992). Various studies

1 Professor, Department of Civil Engineering, National Pingtung University of Science and Technology, Pingtung 91201, Taiwan, +8868 770-3202, ko@mail.npust.edu.tw; President, Lean Construction Institute-Taiwan; Research Director, Lean Construction Institute-Asia.

2 MS, Department of Civil Engineering, National Pingtung University of Science and Technology, Pingtung 91201, Taiwan. 
have proven that lean construction could provide the construction industry with an alternative management philosophy (Koskela 1992; Ballard 2000; Ko and Chen 2012; Ko 2011). Lean construction could break through the limit of the traditional construction cost and time trade-off (Best and de Valence 2000). The purpose of this research is to applying the lean manufacturing to eliminate waste in formwork engineering. This paper first introduces background information of the study. Kanban and Andon systems are explained. Formwork construction practice is then discussed, followed by the development of a lean formwork construction process. Finally, a practical construction project is used to validate the feasibility of the lean formwork model. Conclusions and direction for future research are finally documented.

\title{
BACKGROUND INFORMATION
}

Andon and Kanban have been regarded as lean tools to reduce inventory level and create continuous flow. Both methods are briefly introduced as follows.

\section{KANBAN}

Kanban, in Japanese, refers to signboard, billboard, bulletin board, and card in general (Liker 2003). Kanban originates from the stamping production line of the Toyota manufacturing site ( $\mathrm{Li}$ and Yang 2009a). The post-supplementary production pursued by the stamping production line is regarded as the production signal according to the level of material consumption. The most direct manifestation is to decrease the inventory in the storage yard. Three categories of the Toyota Production System's Kanban are described as follows (Li and Yang 2009b):

- Production Kanban

This is a tool used between the finished goods storage yard and production line. The production Kanban plays a role of triggering the production in the post-supplementary production system.

- Material withdrawal Kanban

This kind of Kanban is used by workers to retrive required parts from the storage yard. In this Kanban, the item and corresponding number of parts to be retrieved is recorded.

- Mark and management Kanbans

This Kanban is a static board put on the production site, and can be divided into two types. One is used for displaying information for everyone. The other is mainly used for displaying managerial data.

\begin{abstract}
ANDON
Andon originates from the automatic loom invented by Sakichi Toyoda. The loom stops and the alarm lamp lights up when the device detects the broken yarns. Toyota Motor uses this concept in quality control. An error sensor is installed in the production equipment, and this equipment stops automatically when the sensor detects a fault. Toyota Motor also authorizes workers to press the button or pull the Andon Cords to stop
\end{abstract}


the production line when they find a problem or need help to solve problems. Nowadays this alarm system represents the signal needing assistance (Liker 2003).

\section{FORMWORK OPERATION PROCESS}

Formwork operational process includes the following 10 steps, namely: 1) planning and designing, 2) shop drawing preparation, 3) material preparation, 4) mold machining, 5) setting out, 6) formwork assembly, 7) inspection, 8) monitoring and remedy of concrete pouring, 9) stripping, and 10) re-supporting of formwork, as shown in Figure 1 (Shen 1996). The general contractor designs the formwork system. Subcontractor then prepares the shop drawing and materials according to the formwork system. Mold inventory and hardware fittings are also enquired by the formwork subcontractor. If the inventory is insufficient, the subcontractor re-orders the required materials from material suppliers. Mold positions are set out before assembly. Formwork subcontractor has to verify the correctness of setting results, therefore molds can be machined and then assembled. Formwork assembly is carried out alternate with third parties, i.e. piping, rebar, and wiring. During pouring concrete into the mold, the formwork subcontractor must send a formwork engineer on site to avoid formwork support collapse and to handle emergencies in case of formwork exploded. Molds are stripped according to building codes. The stripped molds are reused in the site for the forthcoming formwork. Otherwise, they are shipped to the next project or mold storage yard.

Defective formwork systems may result in collapse or structural deformation. The main reason could be imputed to poor quality control, resulting in waste of making defective products. Workers do not fix problems once they have been found may cause formwork collapse or structural deformation when pouring concrete. These problems may cost more finance and manpower to repair and may interrupt production flow. The additional handling procedures and the consumption of time, energy, and costs are waste. 


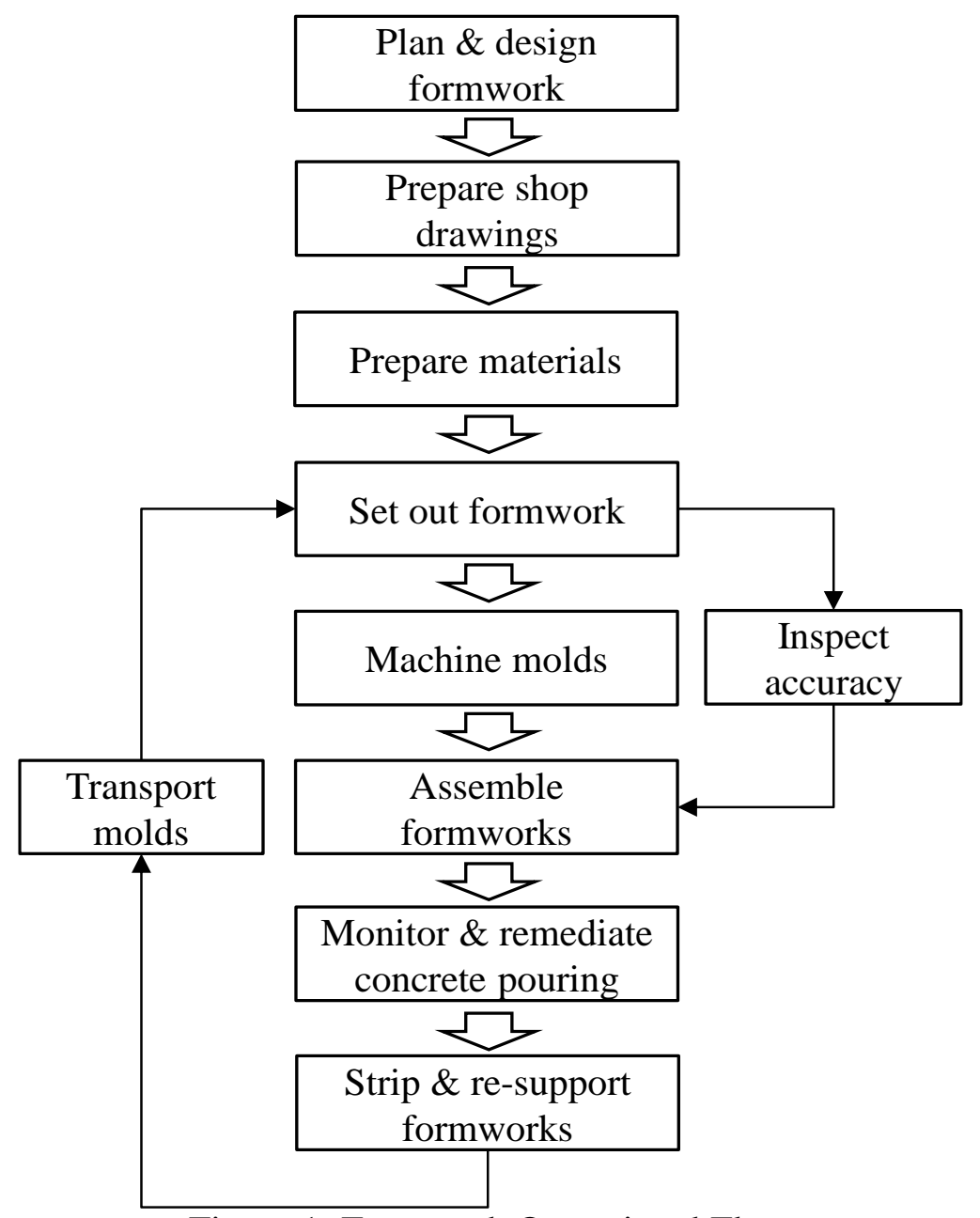

Figure 1: Formwork Operational Flow

\section{LEAN FORMWORK}

Formwork system is constructed according to the design conducted by general contractor. Current practice rarely emphasizes the formwork construction quality, or works out a method for improving the quality based on the formwork nature. As a result, the quality of formwork may be various. Poor formwork system may bulge or even collapse. Furthermore, the arbitrary piled up molds in the storage yard increases the time required to search for and handle them (Peng 1998). In order to improve these problems, this study uses the Andon and Kanban systems to establish the lean formwork construction model. Andon is mainly used for establishing the quality control culture, and the Kanban system is used for reducing material inventory (Ko and Kuo 2015). The framework of the lean formwork construction model is shown in Figure 2. In the figure, Andon and Kanban systems are working independently but coherently. The whole production is driven by Kanban system, while the Andon system is implemented within the Kanban system to improve its quality control. 
The Toyota way attaches importance to the establishment of the quality control culture. When problem occurs in the production system, the production process is stopped immediately until the problem is solved (Liker and Meier 2006). In the proposed model, Andon culture is adopted to help formwork workers stop working and ask for help when problems occur. When establishing this culture, formwork workers are educated that support is available and no one will receive penalty when problems occur. Because workers do not need to worry about penalty, the performance improvement becomes a cooperative altitude. The use of the Andon culture is to develop a quality management system that focuses on doing the quality right at the very beginning. The culture can also help project stakeholders (i.e. general contractor, formwork subcontractor, third parties) identify and solve problems. However, suspension of the formwork progress puts pressure on project delivery and costs. The construction team should jointly look for methods for solving problems. Otherwise the suspension causes excessive waste. Another reason this study adopted Andon culture is that the suspension of production can effectively control the spread of problems. Formwork subcontractors generally attribute mistakes to the workers. By the contrast, in the lean formwork construction model, all mistakes are assumed causing by the improper work system, flow, and methods. When the formwork workers are educated with this culture, the team members can then endeavor to formulate a more effective system rather than defending themselves.

The Kanban system is used for changing the traditional way of orally releasing construction orders. This method can respond customer demands and banish the potential waste of the materials in the storage yard. In addition, the Kanban system can be used as a base for communication and jointly solving problems among superintendents, formwork foreman, and workers. The continuous formwork construction flow can therefore be created for controlling the formwork progress.

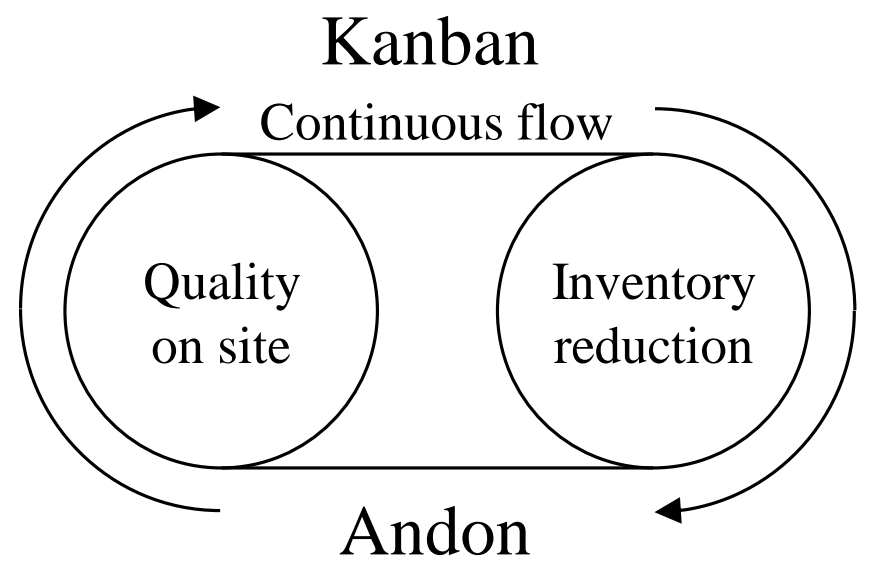

Figure 2: Lean Formwork Schema 


\section{CASE STUDY}

In this paper, a real construction project is used for explaining the feasibility of the proposed lean formwork construction method. The studied case has one basement with four stories. Total floor area of this building is 2185.3 square meters. This study uses the formwork construction in the second floor as an example. The formwork area in the second floor is 1646 square meters. Shaped steel, steel tube supports, wooden supports, and wooden molds are used. Besides above subcontractors, this floor has scaffold, steel bar, electromechanical, and concrete engineering. The formwork worker-hours in this floor are summarized in Table 1. In the table, worker-hours were measured by the time to complete the formwork with design quality.

\section{Table 1: Formwork Construction Worker-Hours}

\begin{tabular}{ccc}
\hline Activity & Workers $^{1}$ & Worker-hours $^{2}$ \\
\hline Set out & 0.5 & 4 \\
Prepare storage yard & 2 & 16 \\
$\begin{array}{c}\text { Assemble and machine } \\
\text { mold } \\
\text { Strip mold }\end{array}$ & 140.5 & 1124 \\
Arrange mold & 26.5 & 212 \\
Transport mold & 14.25 & 114 \\
& 35 & 282
\end{tabular}

${ }^{1} 1$ worker $=1$ worker works for 8 hours.

${ }^{2}$ worker-hours $=$ Workers $* 8$ hours.

In assembling and machining formwork, motions i.e. measure, pull, cut, pass, nail, and mend are categorized as value-adding activities whereas walk, search, and wait are waste. The move motion in the transporting mold produces value; however, waiting to be transported is wasteful. An appropriate site layout can reduce the non-value-adding motions, such as walk and wait in assembling and machining formwork and wait in transporting molds. As a result, work efficiency can be enhanced.

Elimination of the non-value-adding motions of walk, search, and wait in assembling and machining formworks and wait in transporting molds can reduce 570.24 workerhours (i.e. 71.28 workers). The proposed method can reduce 437.28 worker-hours waste (54.66 workers) in assembling and machining formworks; the productivity increases from the initial 11.72 up to 19.18 square meters per worker per day. Regarding transporting molds, the productivity increases from the initial 46.7 to 88.35 square meters per worker per day. Comparisons between before and after improvement are shown in Figure 3. 


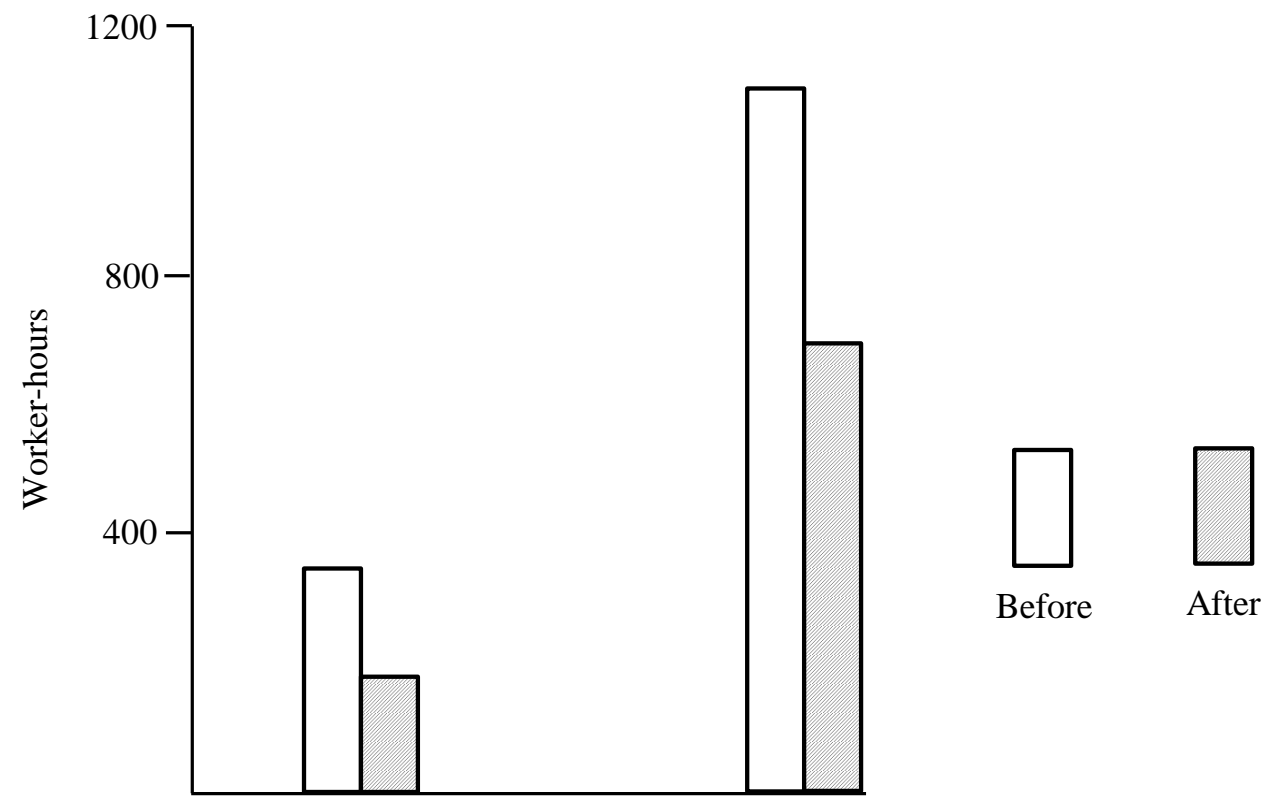

Transport mold $\quad$ Assemble and machine mold

Figure 3: Worker-Hours Improvement

Currently the general contractor, formwork subcontractor, and third party of the project work individually. Such team work culture without an integral plan results waste of waiting between subcontractors due to poor coordination. Analyzed results show that the current formwork construction flow contains waste of motion. Main reason is that the formwork foreman does not plan the construction site layout ahead. Therefore, the waste of motions such as walk, search, and wait occur while assembling, machining, and transporting molds. Furthermore, the construction instruction is orally expressed by the formwork foreman. Formwork workers may receive incomplete production information. Moreover, the formwork team generally lacks of on-site quality control concept. Assistance cannot be obtained when workers have doubts in the construction process. These reasons may generate waste of making defective products.

\section{CONCLUSIONS}

Current practice in formwork assembling, machining, and transporting have much waste. This research uses the lean manufacturing to establish a lean formwork construction model, a formwork production system based on reducing waste while increasing customer value. The formwork construction signal transmitted by Kanban system is then pulled to reduce mold inventory.

Improving formwork quality depends on continuously learning and improvement attitude. The Andon culture and Kanban system can then be used to eliminate the nonadding-value waste. However, when transforming lean into formwork construction process, foremen and superintendents also should take the resistance of change into consideration. Lean education is necessary when implementing the lean formwork 
construction model. Since managerial philosophy between the lean formwork construction model and the current practice is different, workers may resist changing.

\section{REFERENCES}

Arslan, M., Simsek, O., and Subasi, S. (2005). "Effects of formwork surface materials on concrete lateral pressure." Construction and Building Materials, 19(4), 319-325.

Ballard, G., 2000, The Last Planner System of Production Control, The University of Birmingham, PhD Thesis, UK.

Chang, H.C. (2007). Productivity Analysis of Construction Formwork in Residential Buildings, MS Thesis, Department of Civil Engineering, National Taiwan University, Taiwan (in Chinese).

Koskela, L. 1992. Application of the New Production Philosophy to Construction, Technical Report, Stanford University, USA.

Ko, C. H and Chen, Y. C. (2012). "Evaluating Production Time Buffer for Precast Fabrication." Journal of Engineering, Project, and Production Management, 2(2), 101-111.

Ko, C. H. (2011). "Production control in precast fabrication: considering demand variability in production schedules." Canadian Journal of Civil Engineering, 38(2), 191-199.

Ko, C. H. and Kuo, J. D. (2015). "Making Formwork Construction Lean." Journal of Civil Engineering and Management, 21(4), 444-458.

Best and de Valence (Editors), 2000, Building in Value: Project Delivery, John Wiley \& Sons, New York.

Liker, J. K., 2003. The Toyota Way: 14 Management Principles from the World's Greatest Manufacturer. McGraw Hill, New York.

Liker, J. K. and Meier, D., 2006. The Toyota Way Fieldbook, Mc Graw Hill, New York.

Li, H. S. and Yang, C. C. 2009a. Meticulously Discuss Toyota Production System. Quality Monthly Journal, 45(3), 13-18 (in Chinese).

Li, H. S. and Yang, C. C. 2009b. Kanban in Toyota Production System. Quality Monthly Journal, 45(4), 42-49 (in Chinese).

Peng, Y. H. (1998). Consulting Service for Automation in Architectural Engineering, Research Report, Architecture and Building Research Institute, Ministry of the Interior, Taipei, Taiwan (in Chinese).

Shen, C. F. (1996). Formwork Engineering: Economic, Design, Assembly, and Safety. Shen, Taipei (in Chinese).

Sutherland, M. (2005). "Formwork economics." Concrete Engineering International. 9(4), 18-19.

Spottiswoode, A. J., Bank, L. C., and Shapira, A. (2012). "Investigation of paperboard tubes as formwork for concrete bridge decks." Construction and Building Materials, 30, 767-775.

Veenendaal, D., West, M., and Block, P. (2011). "History and overview of fabric formwork: Using fabrics for concrete casting." Structural Concrete, 12(3), 164-177.

Yip, R. and Poon, C. S. (2008). "Comparison of timber and metal formwork systems." Proceedings of Institution of Civil Engineers: Waste and Resource Management, 161(1), 29-36. 